Mayo 2020

\title{
La semiótica como metodología para el estudio de la representación de las enfermedades mentales en las series de TV. Estudio de caso: My Mad Fat Diary
}

\author{
Marta Lopera- Mármol \\ Universitat Pompeu Fabra \\ marta.loperaa@upf.edu \\ ORCID: 0000-0002-0827-4044
}

DOI: $10.31009 /$ methodos.2020.i01.10

Lopera - Mármol, M. (2020). La semiótica como metodología para el estudio de la representación de las enfermedades mentales en las series de TV. Estudio de caso: My Mad Fat Diary. En: Lopezosa, C.; Díaz-Noci, J.; Codina, L. (ed.). Anuario de Métodos de Investigación en Comunicación Social, n.1 (p.106-116). Barcelona: DigiDoc-Universitat Pompeu Fabra

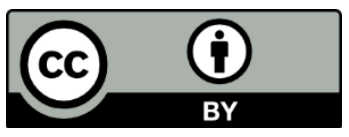





\title{
La semiótica como metodología para el estudio de la representación de las enfermedades mentales en las series de TV. Estudio de caso: My Mad Fat Diary
}

\author{
Marta Lopera- Mármol \\ Universitat Pompeu Fabra \\ marta.loperaa@upf.edu \\ ORCID: 0000-0002-0827-4044
}

\section{RESUMEN}

El presente artículo analiza la representación de las enfermedades mentales, en especial la depresión, en las series televisivas mediante un análisis semiótico del estudio de caso de: My Mad Fat Diary, una serie británica del género del dramedia y el coming-of-age, con un fuerte carácter postmoderno, basada en la nostalgia y el brit-grit. El marco teórico revela que todavía se manejan conceptos erróneos, desinformación, estereotipos, prejuicios y tergiversaciones respecto a la salud mental. Sin embargo, el estado de la cuestión revela que ha habido una pequeña mejora en relación al enfoque durante los últimos veinte años, observables en distintos casos seriales. La metodología de análisis, basada en la semiótica de Greimas y Courtés, nos permite desvelar desde los elementos más superficiales, como la manifestación y el discurso, a los más profundos y trascendentales, como el nivel semio-narrativo y el axiológico. Los resultados y las conclusiones manifiestan que, en My Mad Fat Diary, la representación de la depresión es bastante fidedigna respecto al realismo clínico de la enfermedad, aunque debería mejorarse la representación de muchos aspectos todavía.

\section{PALABRAS CLAVE}

My Mad Fat Diary, enfermedades mentales, depresión, dramedia, brit-grit, coming-of-age, series de televisión y representación.

\section{Semiotics as a methodology for studying the representation of mental illness in TV series. Case Study: My Mad Fat Diary}

La semiòtica com a metodologia per a l'estudi de la representació de les malalties mentals en les sèries de TV. Estudi de cas: My Mad Fat Diary

\section{ABSTRACT}

This article analyzes the representation of mental illnesses, especially depression, in television series through a semiotic analysis of the case study of My Mad Fat Diary, a dramedy and British coming-of-age TV series, with a strong postmodernist character based on nostalgia and brit-grit. The theoretical framework reveals that misconceptions, disinformation, stereotypes, prejudices and misrepresentations regarding mental illnesses are still handled. However, the state of the art reveals that there has been a small improvement concerning the approach of those during the last twenty years, as seen in different serial cases. The methodology based on the semiotics of Greimas and Courtés allows exploring from the most superficial elements, such as manifestation and discourse, to the most profound and transcendental ones, such as the semio-narrative level and the axiological level.

\section{KEYWORDS}

My Mad Fat Diary, mental illness, depression, dramedy, britgrit, coming-of-age, television series and representation

\section{RESUM}

El present article analitza la representació de les malalties mentals, especialment la depressió, en les sèries televisives mitjançant una anàlisi semiòtica de l'estudi de cas de: La meva Mad Fat Diary, una sèrie britànica de el gènere de l'dramèdia i el coming-of-age, amb un fort caràcter postmodern, basada en la nostàlgia $i$ el brit-grit. El marc teòric revela que encara es manegen conceptes erronis, desinformació, estereotips, prejudicis i tergiversacions que fa a la salut mental. No obstant això, l'estat de la qüestió revela que hi ha hagut una petita millora en relació a l'enfocament durant els últims vint anys, observables en diferents casos serials. La metodologia d'anàlisi, basada en la semiòtica de Greimas i Courtés, ens permet desvetllar des dels elements més superficials, com la manifestació i el discurs, als més profunds i transcendentals, com el nivell semio-narratiu i el axiològic.

\section{PARAULES CLAU}

My Mad Fat Diary, malalties mentals, depressió, dramèdia, brit-grit, coming-of-age, sèries de televisió i representació.i 


\section{Introducción}

La investigación y los estudios académicos de las series televisivas comenzaron a ser relevantes a partir de que estas fueran categorizadas como la tercera edad dorada de la televisión (Nahum GarcíaMartínez, 2014). A partir de las teorías de Jason Mittell (2015), entre otros, se reconocerían la complejidad de las estructuras dramáticas y la narrativa, los giros argumentales, las temáticas originales y el tratamiento audiovisual innovador que han tenido estas obras audiovisuales dentro del espectro televisivo. En los últimos 20 años, las series han provocado que la audiencia haya cambiado sus hábitos de consumo y haya sido influenciada en cierto modo por nuevos fenómenos como el fandom, acuñado por Henry Jenkins (2006), el fanfiction y el binge-watching/ binge-viewing/marathon-viewing (Del Campo et al., 2016). Las series televisivas se han reconfigurado en nichos de mercado, muy particulares, provocando que se hayan convertido en "un complejo híbrido de géneros" (Tous Rovirosa, 2015: 5) y viéndose favorecidas por la multiplicidad de nuevos soportes, medios y plataformas en línea como Netflix, Hulu, HBO, etc.

Las series presentan un rol fundamental en nuestra sociedad, dado que se encargan de la transmisión de valores, creencias, estereotipos y actitudes mediante representaciones de diferente índole, a una audiencia amplia y heterogénea, creando un alto grado de compromiso y permitiendo a su vez reflexiones sobre nuestra sociedad contemporánea (Tous Rovirosa, 2015: 2). En vista de que "los contenidos televisivos siguen siendo la principal fuente de medios, no sólo en el ámbito económico sino también en el estético" (Del Campo et al., 2016: 13) se puede afirmar que la ficción televisiva de carácter popular actúa "como micromitos con un gran poder educativo sobre la audiencia" (Tous Rovirosa, 2015: 24) constituyéndose así en un fenómeno cultural, artístico, social y económico.

\section{Series de ficción sobre enfermedades mentales}

Particularmente, en los últimos veinte años las temáticas de las series de ficción sobre las enfermedades mentales han empezado a ser reconocidas por los críticos, los médicos y los educadores, puesto que ven en ellas una herramienta potencial para la educación de la sociedad (Hirt, et al., 2013: 237), categorizándolas dentro de la "era del realismo" (Pintor-Holguín et al., 2012: 162). De acuerdo con la última edición del Manual Diagnóstico y Estadístico de los Trastornos Mentales1, abreviado como DSM-V, se definen las enfermedades mentales "como una alteración del proceso cognitivo y afectivo que impide que la persona que la padece tenga un desarrollo normal". Sin embargo, hay que hacer hincapié en el hecho de que hay múltiples trastornos y enfermedades mentales, con distintas alteraciones cognitivas y afectivas y que no todas se desarrollan y evolucionan de la misma manera.

Muchos artículos académicos han demostrado que las series televisivas tienen un enorme poder para moldear las actitudes del público hacia el tratamiento de las enfermedades mentales (Espanha, 2014). Con respecto a las representaciones negativas, éstas pueden perpetuar estereotipos negativos de las personas que lo padecen, presentándolas como peligrosas, violentas, lunáticas, genios, pero con rasgos temerarios, con dificultades para tener pareja, incapacitadas para trabajar, etc.. Esto se debe al uso de un diálogo peyorativo, a la representación errónea basada en ideas falsas, y/o a la desinformación en la construcción de personajes que padecen un problema de salud mental, o bien a un retrato de espacios no realistas. En consecuencia, esto provoca que se perpetúen ciertas estigmatizaciones y se cree un imaginario social que no converge con la realidad (Couture y Penn, 2003; Pirkis et al., 2006 y Niederkrotenthaler et al., 2014).

En contraste con lo anterior, nuevos estudios académicos muestran que esta tendencia se está intentando revertir mediante nuevas incorporaciones de series televisivas con intención positiva por parte de las "writers' rooms"2 como vemos en Shameless (Showtime, 2011-), Bojack Horseman (Netflix, 2014-), Community (NBC, 2009-2015), etc. que muestran alternativas y consciencia sobre los debates sociales acerca del prejuicio y la discriminación en materia de salud mental.

Es por ello por lo que las representaciones positivas pueden "potencialmente combatir y desafiar ese estigma" y "aumentar la voluntad de interactuar con las personas que lo padecen" (Pirkis et al. 2006; Couture y Penn, 2003 y Wright, 2009) cuando se apuesta por una representación más fidedigna. Estos retratos positivos intentan normalizar los problemas de salud mental mediante la creación de personajes $360^{\circ}$, que deben enfrentarse a desafíos cotidianos, visualizando como éstos son capaces de manejarlos, demostrando así su capacidad para vivir vidas productivas y valoradas.

De esta manera, se permite a la audiencia alejarse del estereotipo simplista de "loco", desafiando así el supuesto común de que existe un vínculo entre la salud mental y la violencia, se apuesta por una representación realista.

Ocasionalmente, no obstante, con el fin de mostrar que estas personas pueden integrarse en la vida social, laboral, política y económica, se puede tender a victimizar y a compadecer a los personajes que sufren un trastorno mental, volviendo a presentar estereotipos donde la persona que padece el trastorno puede 
ser representada nuevamente como un genio, o bien se minimiza tanto su situación, en un intento de aparentar en cierto sentido la misma normalidad e igualdad respecto al resto de personas, que se le resta importancia a la dificultad real que conlleva padecer un trastorno mental, desarrollando así otro tipo de estereotipo que no se ajusta a la realidad clínica de los enfermos mentales (Draaisma, 2009). Eso evidencia de nuevo la dificultad que comporta la erradicación de los estereotipos y la representación fidedigna en relación a la realidad clínica.

Conviene destacar que anteriormente los espacios narrativos en los que se solía mostrar el tratamiento que recibían las personas que padecían enfermedades mentales eran psiquiátricos con instalaciones inhóspitas y despersonalizadas, donde se realizaban prácticas inhumanas, indecentes y crueles, tales como la lobotomización, la sobremedicación, el encadenamiento, etc., visto en filmografías y en series televisivas como: Shutter Island (Scorsese, 2010), Girl, Interrupted (Mangold, 1999), Stranger Things (Netflix, 2017-), etc. Actualmente, nos muestran centros e instituciones más normalizadas, con instalaciones sanitarias como las de cualquier otra rama médica, con espacios íntimos y públicos más acogedores, donde se desarrollan prácticas, terapias y tratamientos más éticos y profesionales.

Nos referimos a In Treatment (HBO, 2008-2010), Atypical (Netflix, 2017-), En Terapia (TV Publica, 2012-2014).

No obstante, aún se refleja la medicación como el mejor tratamiento que puede recibir el paciente. De hecho, se suele presentar a veces como la única alternativa, como si las personas que no las tomaran padecieran de una crisis que solo puede ser solucionada de nuevo con medicación, creando una estructura triangular de "equilibrio-crisisrecuperación" (Harper, 2009: 103)

Finalmente, podríamos sintetizar afirmando que, para muchos espectadores sin experiencia previa, las series televisivas son el primer y único contacto con ciertos trastornos mentales (Espanha, 2014: 9). No obstante, predominan las representaciones inexactas sobre la salud mental y la ausencia de personajes con experiencias positivas (Henderson, 2018: 114). Esto no significa que los medios, canales, plataformas y/o soportes no sientan una responsabilidad social a la hora de producir dramas auténticos sobre la temática, pero estos medios deben buscar un equilibrio entre el ritmo dramático y el realismo, puesto que a su vez tienen que responder a los intereses del mercado audiovisual y a las presiones comerciales en relación a las cifras de audiencia.

\section{My Mad Fat Diary: Brit-grit,}

\section{dramedia, coming-of age y la cruda realidad.}

My Mad Fat Diary (2013-2015) es una serie de televisión británica, emitida en el canal E4, del género del dramedia y centrada en temáticas relativas al concepto de coming-of-age. La historia relata la vida de Rae Earl, una adolescente de 16 años con sobrepeso (pesa 231 libras3), que acaba de salir de un hospital psiquiátrico en el que permaneció cuatro meses internada, debido a una depresión y a un trastorno alimentario (trastorno por atracón). La historia está centrada justo en el momento en que empieza a reincorporarse de nuevo a los ámbitos y a las rutinas diarias y a reanudar la amistad con su mejor amiga de la infancia Chloe. Esta amiga no es consciente del estado de la salud mental de Rae y de los problemas de imagen corporal que tiene, debido a que la familia de la protagonista hizo creer a todos/as que la joven estuvo durante todo ese tiempo en Francia, como si de un periodo vacacional se tratara y ocultando los motivos reales de su internamiento.

Rae intenta evitar que esta información salga a la luz pública, tratando a su vez de impresionar a los amigos de Chloe

- Izzy, Archie, Chop y Finn 4-, con el objetivo de integrarse en la pandilla y así intentar tener una vida como la de cualquier otro adolescente. La serie es, por lo tanto, la narración de la dualidad de los mundos en los que se desenvuelve Rae, el psiquiátrico y el adolescente normalizado del exterior.

No obstante, al final de la primera temporada la información referente a su salud es revelada por la propia Rae, transformando la narrativa en un juego de malabares entre lo que es considerado vida normativa y su enfermedad mental. Es importante remarcar, que la serie de televisión está basada en dos libros escritos por la verdadera Rae Earl:

"My Fat, Mad Teenage Diary (2007)" and "My Fatter and Madder Teenager Diary" (2014). La historia se sitúa en la ciudad de Stamford (en el condado de Lincolnshire), potenciando el carácter brit-grit ampliamente explorado por E4 en series televisivas como Derry Girls (2018-), Skins (2007-2013), Misfits (2009-2013), etc. El brit-grit es la representación de "una identidad nacional y cultural ante una audiencia internacional" (Lay, 2002) mediante la visualización de costumbres, planteando algunos de los problemas y las fisuras de los sistemas de valor dentro del marco de la democracia social británica. Este fenómeno se ve enfatizado por el carácter nostálgico de la serie que, basada en los años 1996 y 1998, cuenta con una banda sonora britpop, con grupos como The Charlatans, Oasis, The Cure, Blurr, Radiohead, etc. 
El hecho de que My Mad Fat Diary se conciba dentro del género del coming-of-age, ese viaje de crecimiento personal de un o una protagonista que transcurre desde la adolescencia hacía la edad adulta, propicia la enfatización de los diálogos y monólogos internos, las palabras ante las acciones, dando voz a los adultos jóvenes con temáticas, desafíos y triunfos de la adolescencia de carácter universal como la amistad, los primeros amores, la búsqueda de un propósito y un lugar en el mundo, encarándolo desde múltiples puntos de vista: cómicos, dramáticos, documentales, románticos, etc. Además, se aprecia cómo los acontecimientos que nos conforman a medida que crecemos nos siguen afectando y moldeando a medida que vivimos y maduramos. Teniendo en cuenta estas cuestiones, observamos que el coming-of-age nos permite la exploración de la enfermedad mental desde muchas y diferentes vertientes para profundizar en las diversas y complejas situaciones emocionales. Particularmente, en el caso de My Mad Fat Diary se nos muestra con mucha facilidad el mundo interior de la protagonista, puesto que proviene del diálogo sincero y continuo que ella mantiene y escribe íntimamente en su diario.

\section{Metodología}

El estudio de las series televisivas parte de una multiplicidad de metodologías y necesita de distintos tipos de análisis para su estudio debido a dos razones fundamentalmente, por un lado la complejidad en su desarrollo narrativo, no sólo en cuanto a la temática principal, sino también en relación a las historias secundarias que la rodean y con las que interactúa la principal; $y$, por otro lado, a la variedad de los géneros de ficción a los que se pueden recurrir. No obstante, hay algunas que destacan por encima de otras, por su relevancia y por la capacidad de análisis completo.

Este artículo como se ha mencionado previamente, tiene como objetivo exponer qué tipos de instrumentos proporciona la semiología o semiótica aplicada a las series televisivas de ficción.

La semiología o semiótica (del griego: "simiotikos") es la ciencia derivada de la filosofía y la disciplina que se ocupa del estudio comparativo de los sistemas de signos. Las funciones principales del sistema de signos son: 1) la transmisión de comunicación o de expresión del sentido (Significación y sentido); 2) la comunicación, es decir, la seguridad de la comprensión por el oyente y/o lector de la noticia transmitida, así como la estimulación para la acción y la influencia emocional, que trata de los sistemas de comunicación dentro de las sociedades humanas, estudiando las propiedades generales de los sistemas de signos, como base para la comprensión de toda actividad humana (Diccionario de filosofía, 1984: 386-387).
La semiótica ha tenido una repercusión importante en los estudios del lenguaje, la comunicación humana, y los fenómenos psicológicos y sociales generados mediante la comunicación. En otras palabras, la semiótica es el estudio articularmente, en los últimos veinte años las temáticas de las de los signos, que nos ofrece un punto de vista sobre la realidad, y sobre el modo en que las cosas adquieren y transmiten un significado (Diccionario de filosofía, 1984: 386-387). En el presente artículo se trabajará con un análisis semiótico basado en Greimas y Courtés, puesto que es uno de los análisis más usados en las series televisivas.

Parte de cuatro niveles distintos que nos permiten profundizar en el núcleo de la significación. Estos niveles son: (1) el de la manifestación, el más superficial, el cual corresponde a saber cómo se ha llevado a cabo el nivel discursivo; (2) el discursivo que corresponde a la forma narrativa, la actoralización, la temporización, la espacialización y la contextualización, (3) el nivel de la semio-narrativa que corresponde a la estructura y el desarrollo narrativo; y finalmente (4) el nivel axiológico que corresponde al núcleo de significación (valores) de la historia. Realizaremos este análisis semiótico basándonos en el retrato del personaje principal, Rae Earl. Para ello se ha realizado un esquema que destaca los principales rasgos de su aspecto físico, su apariencia, su carácter y el desarrollo que sigue el personaje. Los mismos aspectos, aunque sea a grandes rasgos se analizarán también en el resto de los personajes. El uso de esta metodología deriva de la posibilidad de permitirnos buscar una estructura semántica, así como ofrecernos la posibilidad de trazar un análisis de los componentes y los roles actanciales que concurren en las prácticas narrativas audiovisuales (oposiciones entre personajes, espacios y fases de la historia).

En el análisis semio-narrativo, trata de revelar la fase de desajuste (aquella que ha llevado a los personajes a la situación actual), en estos casos es necesario especificar quiénes son: el sujeto del desajuste (quién sufre el problema), el agente de desajuste (quién causa el problema), el focalizador (el encargado de dirigir la acción) y el contrafocalizador (el que intenta evitar y/o restar la acción del focalizador). Una vez se resuelve la fase de desajuste, intervienen dos actantes: los actantes principales corresponden al destinador también llamado beneficiario en narratología (que es quien participa como fuente y origen de un saber o de un pre-saber y que en cierta medida suscita las acciones del relato para obtener un objeto de valor, en ocasiones puede ser el mismo sujeto de la acción). El sujeto de acción/ receptor (que es quien recibe la acción) y el objeto de valor (corresponde al objeto del deseo). Para poder lograr el objeto de valor, el sujeto de acción debe adquirir determinadas competencias: motivaciones -voluntad (querer) y deber- y capacidades -conocimiento (saber) y poder. Una vez 
estas competencias son conseguidas, se ejecutará la acción (performance) que es impulsada por pasiones o creencias que recaerán sobre el sujeto de estado.

El sujeto de estado (es el receptor de la acción). Éste puede ser un individuo, (corresponde a una persona), colectivo (corresponde a un grupo de personas), figurativo (representa personas $\mathrm{y} / \mathrm{u}$ objetos de forma real y reconocible), abstracto (representa seres $u$ objetos no-concretos), natural (que forma parte de la naturaleza de algo y es propio y característico de ello), sobrenatural (aquella persona, objeto o cosa que no puede explicarse por las leyes de la naturaleza o que supera sus límites).

Los actantes secundarios corresponden a la fase de la manipulación, en la que se utiliza la provocación, la seducción, la promesa y/o la amenaza a un sujeto de acción, y que deriva hacia la fase del contrato de enunciación (que es el acuerdo entre dos o más partes en las que los/las participantes admiten y se comprometen a cumplir sus obligaciones o promesas de forma recíproca). Cabe destacar que normalmente "la mayoría de los relatos presentan un contrato mal respetado que degenera en historia" (González, 1999: 234). Por otra parte, en los actantes secundarios se encuentran: los adyuvantes (ayuda al sujeto a alcanzar su objetivo) y/o los oponentes (que obstruye la realización del programa narrativo del sujeto) o un anti-sujeto (que es aquel que busca el mismo objeto de valor que el sujeto de acción, unque sólo uno de ellos puede tener éxito). Una vez que se alcanza el objeto de valor, se ingresa en la fase de sanción. En la que, si el contrato se cumple, se pueden dar dos situaciones: la del reconocimiento (positivo o negativo) y la de retribución (que puede ser una recompensa o un castigo). En esta fase se presentan dos nuevos roles: el sancionador (productor de las consecuencias) y el sancionado (receptor de las consecuencias).

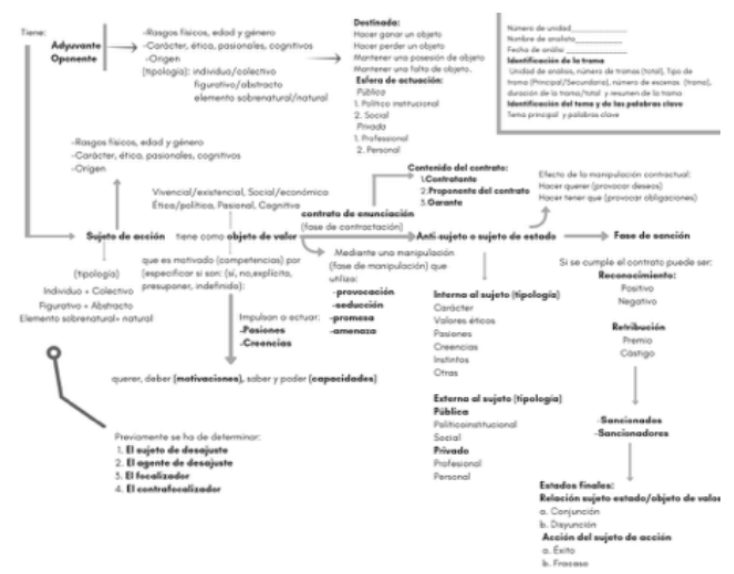

Figura 1. Esquema resumen de la metodología de análisis. Fuente: elaboración propia.
La relación del sujeto del estado y el objeto de valor se puede presentar como una conjunción o una disyunción y la acción como un éxito o un fracaso.

\section{Resultados}

\section{a) Especificación de los rasgos físicos y apariencia, el carácter, la tipología y la esfera de actuación de los personajes correspondientes a la primera fase del análisis.}

Rae es la protagonista de My Mad Fat Diary. A nivel físico es una chica joven de 16 años, caucásica de origen británico, con sobrepeso, pelo negro y largo, ojos marrones y vestuario rockero, siendo su prenda fetiche una cazadora de piel negra. Por tanto, nos referimos a ella mediante una tipología individual, natural y figurativa. Su carácter viene definido por sus relaciones familiares, sociales y amorosas. Rae proviene de una familia desestructurada y de clase trabajadora. Su padre con hábitos alcohólicos la abandonó cuando era tan solo una niña, quedando bajo la tutela de su madre, enfermera de profesión, que a su vez también tiene problemas con su propia imagen corporal. Ya desde el inicio de la serie se incorpora a la vida familiar, aunque de forma clandestina, el reciente novio tunecino de la madre que se encuentra en una situación de inmigración ilegal. No obstante, tanto la madre como el padrastro de Rae se preocupan constantemente por ella. Rae es una amante de la música britpop y del rock. Sus amigos son una constante en su vida diaria, y considera que la lealtad es lo principal en una amistad, de ahí que ésta sea una de las características más destacada de su grupo de amigos.

Sin embargo, al igual que le ocurre a su madre, Rae siente la necesidad constante de la aprobación masculina, probablemente debido al abandono de su padre biológico tal y como deja entrever la serie; y que se manifiesta repetitivamente en su relación amorosa con Finn, durante toda la serie. Rae sufre depresión y tienen un trastorno alimentario debido a los atracones e ingestas compulsivas de alimentos, por lo general poco saludables, que realiza y que la conllevan a tener sobrepeso, circunstancia que incide en su baja autoestima y falta de amor propio, que normalmente manifiesta mediante pensamientos negativos y de desprecio sobre su cuerpo. También padece de ataques de ansiedad (que la paralizan), se autolesiona en los momentos de dolor emocional o impotencia. No únicamente tiene pensamientos suicidas, sino que los ha puesto en práctica aunque de forma fallida (ésta fue la razón de su internamiento).

No obstante, es una chica que con los demás siempre se muestra sonriente, sarcástica, divertida e inocente. Tiene tendencia a estar absorta en sí misma, usado en la serie para enfatizar los rasgos propios de la 
adolescencia y del coming-of-age; aunque intenta ser consciente de los sentimientos de sus allegados y de estar presente en las situaciones difíciles que viven los demás.

La siguiente tabla se elabora para describir los rasgos físicos, la apariencia, el origen, los aspectos raciales, el carácter, la esfera de actuación (entendida como la implicación de los personajes en los aspectos de la vida de Rae) que puede ser privada, personal, profesional, social, pública, política e institucional. Finalmente, también se indican las tipologías en relación al sujeto de estado tal y como se mencionaba en la explicación del análisis semio-narrativo.

\begin{tabular}{|c|c|c|c|c|c|}
\hline $\begin{array}{c}\text { Personaje } \\
s\end{array}$ & Rasgos fisicos $\mathrm{y}$ apariencia & $\begin{array}{l}\text { Origen y } \\
\text { aspectos } \\
\text { raciales }\end{array}$ & Carácter & $\begin{array}{l}\text { Tipologí } \\
\text { a }\end{array}$ & $\begin{array}{l}\text { Esfera de } \\
\text { actuación }\end{array}$ \\
\hline Finn & $\begin{array}{l}\text { Chico de } 16 \text { años, ojos } \\
\text { marrones, atractivo, pelo } \\
\text { castaño, vestimenta rock de } \\
\text { los } 90 .\end{array}$ & $\begin{array}{l}\text { caucásico } \\
\text { de origen } \\
\text { británico }\end{array}$ & $\begin{array}{l}\text { Sensible, leal, } \\
\text { apasionado, } \\
\text { melómano rockero, } \\
\text { amable, carińoso y } \\
\text { desprovisto de } \\
\text { prejuicios sociales. }\end{array}$ & $\begin{array}{l}\text { individuo } \\
\text { figurativo } \\
\text { natural }\end{array}$ & $\begin{array}{l}\text { privada } \\
\text { personal }\end{array}$ \\
\hline Archie & $\begin{array}{l}\text { Chico de } 16 \text { años, ojos azules, } \\
\text { atractivo, pelo castanio, } \\
\text { vestimenta "nerd" de los } 90 .\end{array}$ & $\begin{array}{l}\text { caucásico } \\
\text { de origen } \\
\text { británico }\end{array}$ & $\begin{array}{l}\text { Sensible, melómano } \\
\text { rockero, leal, tímido, } \\
\text { contradictorio e } \\
\text { indeciso, sobre todo } \\
\text { en relación a su } \\
\text { orientación sexual: } \\
\text { oculta al principio por } \\
\text { temor al rechazo por } \\
\text { ser homosexual. }\end{array}$ & $\begin{array}{l}\text { individuo } \\
\text { figurativo } \\
\text { natural }\end{array}$ & $\begin{array}{l}\text { privada } \\
\text { personal }\end{array}$ \\
\hline Chloe & $\begin{array}{l}\text { Chica de } 16 \text { años, ojos } \\
\text { marrones, pelo castanio, } \\
\text { considerada la más atractiva } \\
\text { del grupo } \\
\text { (heteronormatividad), viste las } \\
\text { últimas tendencias del estilo } \\
\text { brit-grit. }\end{array}$ & $\begin{array}{l}\text { caucásica } \\
\text { de origen } \\
\text { británicos }\end{array}$ & $\begin{array}{l}\text { Sensible, kal, baja } \\
\text { autoestima (por sufrir } \\
\text { la presión que la } \\
\text { sociedad } \\
\text { heteropatriarcal le } \\
\text { demanda, en cuanto a } \\
\text { su fisico y su actitud } \\
\text { ante las relaciones } \\
\text { amorosas). Los } \\
\text { acontecimientos y el } \\
\text { desarrollo hacia su } \\
\text { madurez la convierten } \\
\text { en una mujer fuerte al } \\
\text { enfrentarse a ello. }\end{array}$ & $\begin{array}{l}\text { individuo } \\
\text { figurativo } \\
\text { natural }\end{array}$ & $\begin{array}{l}\text { privada } \\
\text { personal }\end{array}$ \\
\hline Ixxy & $\begin{array}{l}\text { Chica de } 16 \text { años, ojos azules, } \\
\text { pelo pelirrojo, de } \\
\text { indumentaria hippic. }\end{array}$ & $\begin{array}{l}\text { caucásica } \\
\text { de origen } \\
\text { britínicos }\end{array}$ & $\begin{array}{l}\text { Sensible, inocente, } \\
\text { simpática e ingenua. }\end{array}$ & $\begin{array}{l}\text { individuo } \\
\text { figurativo } \\
\text { natural }\end{array}$ & $\begin{array}{l}\text { privada } \\
\text { personal }\end{array}$ \\
\hline Chop & $\begin{array}{l}\text { Chico de } 16 \text { ańos, ojas } \\
\text { marrones, pelo castanio, } \\
\text { dicntes spparados (brecha } \\
\text { dental, denotaría situación } \\
\text { económica moodesta) } y \\
\text { vestimenta obrera para } \\
\text { reforzar la estética brit-grit. }\end{array}$ & $\begin{array}{l}\text { cancásico } \\
\text { de origen } \\
\text { británicos }\end{array}$ & $\begin{array}{l}\text { Divertido, celoso e } \\
\text { ignorante. }\end{array}$ & $\begin{array}{l}\text { individuo } \\
\text { figurativo } \\
\text { natural }\end{array}$ & $\begin{array}{l}\text { privada } \\
\text { personal }\end{array}$ \\
\hline Liam & $\begin{array}{l}\text { Chico de } 16 \text { ańos, ojos } \\
\text { marrones, obeso, pelo castaño, } \\
\text { vestimenta rock de los } 90 .\end{array}$ & $\begin{array}{l}\text { caucásico } \\
\text { de origen } \\
\text { británicos }\end{array}$ & $\begin{array}{l}\text { Rebelde, depresivo, } \\
\text { sarcístico, inscguro } \\
\text { por sua aspecto físios, } \\
\text { leal, (conoce los dos } \\
\text { mundos de Rae y en } \\
\text { ningún momento lo } \\
\text { revela, ni la traiciona) } \\
\text { baja autoestima. }\end{array}$ & $\begin{array}{l}\text { individuo } \\
\text { figurativo } \\
\text { natural }\end{array}$ & $\begin{array}{l}\text { privada } \\
\text { personal }\end{array}$ \\
\hline $\begin{array}{l}\text { Madre de } \\
\text { Rae }\end{array}$ & $\begin{array}{l}\text { Mujer de } 40 \text { años, rubia, con } \\
\text { un poco de sobrepeso, ojos } \\
\text { axules }\end{array}$ & $\begin{array}{l}\text { caucásica } \\
\text { de origen } \\
\text { británicos }\end{array}$ & $\begin{array}{l}\text { Ignorante, maternal, } \\
\text { sarcística, } \\
\text { emocionalmente } \\
\text { dependientey } \\
\text { malhumorada. }\end{array}$ & $\begin{array}{l}\text { individuo } \\
\text { figurativo } \\
\text { natural }\end{array}$ & $\begin{array}{l}\text { privada } \\
\text { personal }\end{array}$ \\
\hline
\end{tabular}
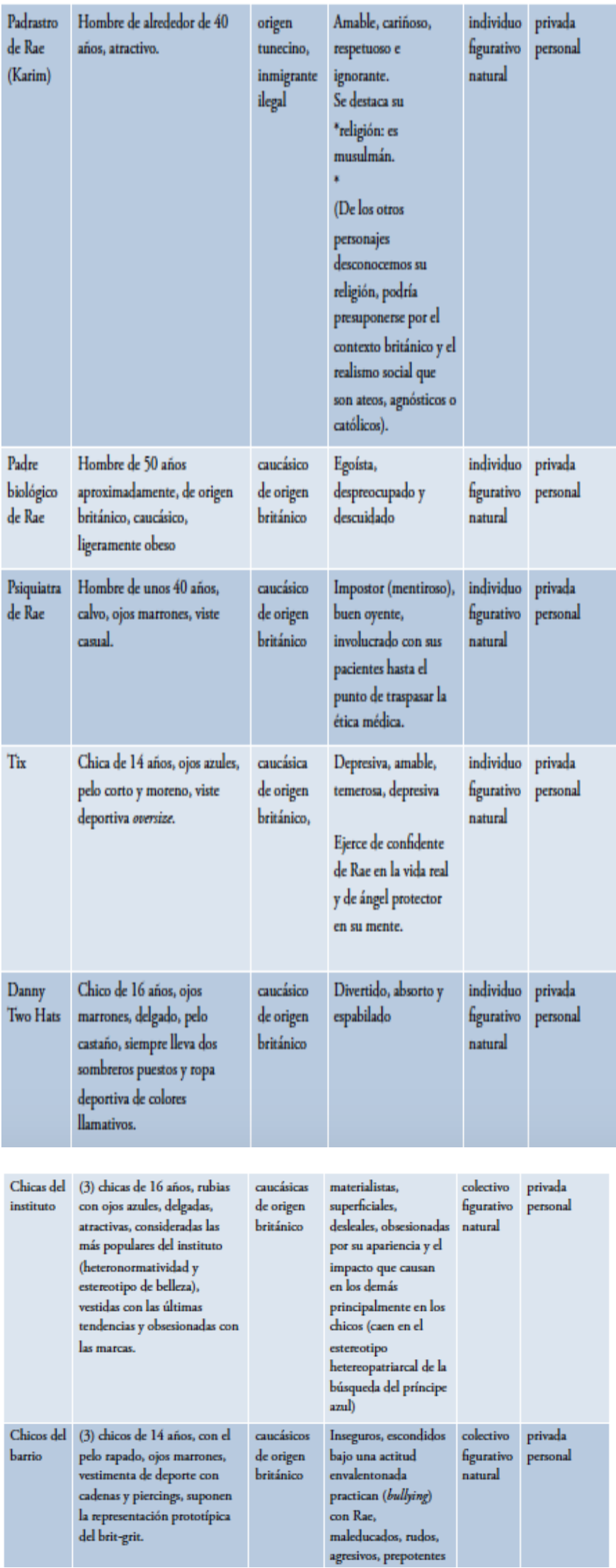

\begin{tabular}{|c|c|c|}
\hline $\begin{array}{l}\text { materialistas, } \\
\text { superficiales, } \\
\text { desleales, obsesionadas } \\
\text { por su apariencia y d } \\
\text { impacto que causan } \\
\text { en los demás } \\
\text { principalmente en los } \\
\text { dhicos (caen en el } \\
\text { estereotipo } \\
\text { hetereopatriarcal de la } \\
\text { búisqueda del príncipe } \\
\text { azul) }\end{array}$ & $\begin{array}{l}\text { colectivo } \\
\text { figurativo } \\
\text { natural }\end{array}$ & $\begin{array}{l}\text { privada } \\
\text { personal }\end{array}$ \\
\hline $\begin{array}{l}\text { Inseguros, escondidos } \\
\text { bajo una actitud } \\
\text { envalentonada } \\
\text { practican (bulljing) } \\
\text { con Rar, } \\
\text { maleducados, rudos, } \\
\text { agresivos, prepotentes }\end{array}$ & $\begin{array}{l}\text { colectivo } \\
\text { figurativo } \\
\text { natural }\end{array}$ & $\begin{array}{l}\text { privada } \\
\text { personal }\end{array}$ \\
\hline
\end{tabular}

Figura 2. Tabla resumen de las unidades e identificaciones analizadas. Fuente: elaboración propia. 
Hemos observado que una de las columnas está dedicada al origen y los aspectos raciales y aunque, en muchas de las obras audiovisuales del canal E4 como Misfits (2009-2013), Skins (2007-2013), Black Mirror (2011-), etc., intentan apostar por un tratamiento racial positivo. Es importante destacar que no siempre lo consiguen. Tal como señalan los resultados, en My Mad Fat Diary tiende a ser negativo puesto que el único personaje no caucásico es un inmigrante ilegal, usado como comic relief y que se casa por amor pero también para conseguir la legalización. El aspecto religioso lo practica de una forma muy impositiva, Karim es de religión musulmana, y la madre de Rae no sólo se convierte en su mujer, sino que también se convertirá a la religión musulmana, la misma que no se cuestionan y bajo la cual educaran a la hija de ambos recién nacida.

\section{b) Análisis de los niveles}

\section{-Nivel de manifestación y discursivo}

Durante el transcurso de la serie podemos delimitar que el nivel de la manifestación y el nivel discursivo suceden en diferentes espacios, que son escogidos para permitir profundizar en el imaginario social del personaje de Rae. Todos estos espacios están ubicados en Lincolnshire. De los espacios del mundo exterior de la protagonista el más concurrido es el pub, punto de encuentro y principal centro de la relación social de la pandilla y que permite hacer hincapié en el concepto de brit-grit, al que no se pretende criticar, sino mostrarlo tal cual, como una realidad social existente, con una estética pueblerina, perdedora y abandonada.

Otro lugar destacable es la tienda de discos donde Rae trabaja, la audiencia es conocedora durante toda la serie de la pasión de Rae por la música, a la vez que el lugar permite también enfatizar en el engagement emocional mediante la nostalgia por los grupos musicales de los 90 . También puede señalarse el instituto, escenario del mundo adolescente del coming-of-age, donde se desenvuelven a diario estos jóvenes en la búsqueda de su identidad, de su desarrollo personal, donde comparten sus vivencias, donde se evidencian y acentúan los problemas de las relaciones sociales de los jóvenes en general y de la protagonista en particular. Aparecen también otros espacios que son presentados con fines puramente narrativos de continuidad cotidiana o rutinaria: la calle, el parque, el gimnasio, los restaurantes, etc.

En relación al mundo interior de Rae, los espacios más remarcables son por un lado, el centro psiquiátrico desde donde se permite entender el trastorno mental del personaje, su evolución mediante el tratamiento psiquiátrico, a la vez que nos facilita conocer todos sus pensamientos y miedos al interactuar con los profesionales médicos y otros pacientes en las terapias individuales y/o colectivas (grupo de apoyo). Además, la institución psiquiátrica nos permite observar otro tipo de relaciones sociales de Rae, las que establece con Tix, Danny Two Hats y Liam (que empieza siendo adyuvante pero debido a su enfermedad mental acabará siendo oponente) en las que no hay filtros sobre su enfermedad mental, facilitando la exploración total de la enfermedad. Y, por otro lado, la casa de Rae, donde se desarrolla la relación problemática que mantiene con su madre (por otra parte, algo propio en la edad adolescente) y su padrastro Karim. Este escenario otorga a la audiencia la oportunidad de conocer el espacio más íntimo de la protagonista: su habitación; y su ambiente claramente adolescente con pósteres de su grupo de música favorito, la comida que esconde en los cajones; etc. Por tanto, su habitación actúa también como el refugio del mundo exterior para distanciarse de todo y de todos. Esa habitación que será el lugar de sus primeros escarceos amorosos.

En cuanto a la temporización, a nivel macro de la historia se contextualiza en 1996, como parte de una estrategia de marketing para atraer a un público "millennial", como mencionaba previamente, apelando a la nostalgia mediante la música, el contexto histórico pre-redes sociales, y el género del coming-of-age y por tanto suscitando interés a un público que ha vivido todo ello. La micro historia transcurre durante dos años, los correspondientes a los de los estudios previos a la universidad.

\section{-Nivel semio-narrativo y axiológico}

Para llevar a cabo el siguiente análisis, se utiliza el esquema que propone este artículo, así como su correspondiente explicación.

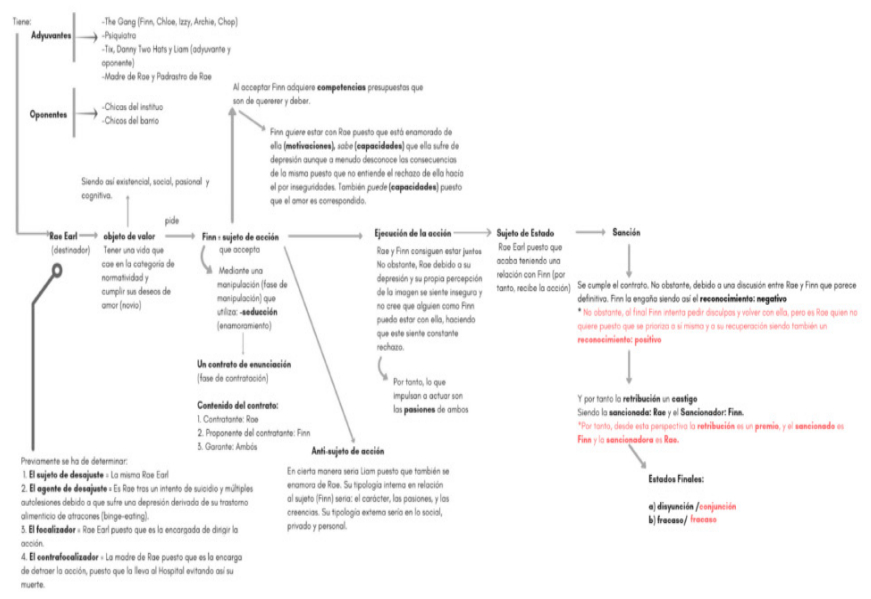

Figura 3. Esquema resumen de la metodología de análisis aplicado. Fuente: elaboración propia..

Tal y como se muestra en el esquema, Rae (sujeto, agente y focalizador de desajuste), tras un intento de suicidio y múltiples autolesiones debido a su depresión, derivada de su trastorno alimenticio por atracones, conocido en terminología anglosajona como binge-eating, termina en un centro psiquiátrico, 
puesto que su madre (contrafocalizador y adyuvante) evita la muerte y apuesta por la recuperación de la joven.

Rae es la destinadora de la acción puesto que, es el elemento que guía toda la narrativa, ella trata de obtener un objeto de valor que, en este caso, significa tener una vida adolescente que encaje dentro de la normatividad social y cumplir sus deseos amorosos en una relación correspondida con Finn (adyuvante). Éste último es, por tanto, el sujeto de acción que acepta el contrato, es decir, mantener una relación, siendo así el proponente y el garante, debido a una fase de manipulación que utiliza la seducción en este caso de Rae que es también la contratante. Finn adquiere las competencias explícitas de querer puesto que, está enamorado de ella y por tanto está motivado por sus pasiones, además puede hacerlo puesto que este interés es correspondido y además es consciente (sabe) que Rae sufre una depresión, que ha estado ingresada, aunque a menudo desconoce las consecuencias de la misma enfermedad, en ocasiones se siente rechazado sin entender que ese rechazo en realidad proviene de la baja autoestima de la protagonista y del sufrimiento que a ella le provoca su imagen corporal como un cierto miedo o sentido del ridículo al pensar que pensaran los demás de que ellos tengan una relación, es decir, la percepción social de su relación amorosa. Cabe destacar que el anti-sujeto de acción sería en un momento determinado Liam (adyuvante que se convertirá en oponente), después de que Rae rechazara a Finn por miedo a que éste ya no le correspondiera. Liam y Rae empiezan una relación amorosa basada en una atracción mutua de sus propios estados de ánimo, ambos sufren una depresión y comparten una problemática causada por su imagen corporal. Sin embargo, el desarrollo de la misma no avanzará, puesto que sus procesos de superación están desfasados en el tiempo, mientras Rae piensa que su similar aspecto físico puede ser un trampolín de ayuda para aceptar sus propios cuerpos, Liam no permite que esto suceda al proponer realizar sexo vestidos, evidenciando el rechazo hacia sus cuerpos, actitud claramente no favorecedora. Rae decepcionada por ello y con afán de superarse a sí misma, no quiere dejar que un hombre la continúe limitando en un aspecto que ella quiere superar, y decide terminar la relación, iniciando así su camino como mujer empoderada. Este último concepto se verá reforzado y se seguirá ejerciendo cuando ella acepte el reto de ir a la universidad, siendo la primera de su familia. Aceptar el reto de ir a la universidad no es únicamente una decisión personal de Rae para su desarrollo intelectual, su capacitación o profesionalización, sino que forma parte de una proyección familiar que lo siente como un ascenso social, teniendo en cuenta su procedencia modesta, sería un triunfo del propio brit-grit y de su ideario de izquierdas que rompe barreras sociales.
Por tanto, la ejecución de la acción es que Rae y Finn consiguen estar juntos, siendo consecuentemente Rae (sujeto de estado). No obstante, se dan numerosos altibajos, que dotan de dinamismo el desarrollo de la narrativa. En una de sus múltiples discusiones debido a la inseguridad de Rae, Finn la engaña con otra chica. Rae lo descubre y pone fin a la relación, que termina comportando la sanción con un reconocimiento negativo, puesto que la relación entre ambos no tiene éxito y por tanto la retribución es un castigo, en la que el sancionador es Finn y la sancionada es Rae, provocando una disyunción y un fracaso entre la relación amorosa de ambos. Sin embargo, teniendo en cuenta que esta serie cuenta con una perspectiva feminista, observamos como en el estado final, ella al final realmente no obtiene ningún castigo, al contrario, consigue reconocimiento y éxito. Aunque cabe destacar, que en una ocasión en particular está a punto de perderlo todo, cuando se niega a sí misma la oportunidad de ir a la universidad para estar con Finn y así negarse la oportunidad de avanzar de forma personal y profesional. Sin embargo, gracias al apoyo e insistencia de su psiquiatra, familia e incluso del propio Finn, decide escoger su propio camino, puesto que finalmente entiende que, para poder superar su enfermedad, poder ser una mujer empoderada y referente para su hermana pequeña, deberá revalorizarse a sí misma, y conseguir primero su propia aprobación.

Cabe apuntar que como se observa en el esquema, la pandilla (The Gang), el psiquiatra, sus amigos del psiquiátrico (Tix y Danny Two Hats) son adyuvantes mientras que las chicas del instituto y los chicos de su barrio son oponentes.

\section{Conclusiones}

My Mad Fat Diary se enmarca dentro de la tendencia de $\mathrm{E} 4$ de representar un realismo social británico fidedigno, así como su intención por apostar por una mejor representación de la salud mental, tanto en los personajes que la padecen como en la actitud de los que los rodean. Para ello, utilizan una estética y narrativa audiovisual compleja con tramas dramáticas y cómicas que deben saber compaginar, subtramas con historias colectivas, flashbacks, flashfowards, y recursos estéticos como el uso de garabatos, gráficos e infografías superpuestas, permitiendo así al espectador profundizar en la exploración de los distintos agentes de las enfermedades mentales. La serie, como se ha mencionado previamente, se presenta en un formato de diario personal: Rae escribe su diario como un medio de terapia, los garabatos y las caricaturas del libro cobran vida en la pantalla, permitiendo a Rae escapar y ser honesta $\mathrm{y}$ al espectador adentrarse en su mundo interior. Un mundo donde a veces su honestidad es un poco ruda, 
como cuando habla de un chico al que quiere que "baje ahí abajo durante tanto tiempo que desarrolle agallas" (2x01). La protagonista es sincera acerca de su lujuria: "La policía de la vagina debería venir y quitarme mis derechos" (2x04). Pero es una prueba de la destreza de Rae y de la serie a la hora de abordar problemas graves como las enfermedades mentales, la depresión, el suicidio, la imagen corporal, el sexo y el feminismo con un encanto e ingenio que podría haberse perdido en el tratamiento narrativo.

El entorno de Rae es bastante favorable a pesar de "enmarcarse" en este brit-grit, como comentábamos previamente.

El acceso a la sanidad y educación pública están presentes como parte de su realidad social. Además, la mayoría de agentes actúan como adyuvantes, que permiten contrarrestar los oponentes. En otras palabras, Rae cuenta con un grupo de amigos leales como se puede apreciar a lo largo de la serie. Sin embargo, Chloe y Finn ejercen, a veces, un carácter excesivamente protector sobre Rae. Finn la defiende ante los chicos del instituto que la llaman Jabba, en referencia al personaje de la saga de Star Wars el Retorno del Jedi (20th Century Fox, 1983), y la quiere con todas sus virtudes y defectos. Con Chloe en primera instancia se muestran como competidoras por la popularidad y la atención de Finn; no obstante, tanto la una como la otra se ayudan siempre en los peores momentos y se mantienen leales la una a la otra. Chloe defiende a Rae delante del grupo de chicas del instituto, y Rae primero saca a Chloe de la relación tóxica que mantiene con un profesor, que la llevará a realizar un aborto; y más adelante la sacará de otra relación humillante para Chloe, la que mantiene sometida a otros jóvenes, a nivel sexual, únicamente para sentirse popular y aceptada. Reforzando así el concepto de sororidad y la perspectiva feminista de la serie. Sin embargo, teniendo en cuenta que se trata de una serie del género del coming-of-age, no deja de ser una puesta en escena, precisamente la etapa de la adolescencia se caracteriza por el compendio de inseguridades de los adolescentes y que en la serie muestran todos los personajes.

La serie se presenta dentro del género dramedia y del coming-of-age, como muchas producciones de la cadena, permitiendo así explorar una narrativa que se basa en un viaje de descubrimiento, en este caso, personal femenino y de superación, dónde se exploran los actos y posicionamientos propios de la adolescencia: menores de edad bebiendo, aborto, miedo al futuro, el sexo está implícito, el idioma callejero con terminología vulgar como: "fuck" y "shit", etc. My Mad Fat Diary, es una serie con tono feminista en contra de los discursos convencionales, mostrando una protagonista que no se enmarca dentro del modelo estándar femenino, que padece de depresión y problemas de imagen corporal, que es presentada con un cuerpo no normativo, poco atractiva y con sobrepeso, además de un carácter directo y sarcástico rompiendo con los cánones sociales mediáticos previos y los roles de género establecidos en los medios, como la delgadez, el comportamiento girlie, la dependencia, la búsqueda del príncipe azul, etc. Sin embargo, Rae es una mujer divertida, capaz e independiente, que no deja de sufrir los temores adolescentes habituales con un agudo sentido del humor.

La serie hace hincapié en la necesidad de demostrar la belleza real de las personas, independientemente del físico, también lo muestra así el personaje de Chloe, que pese a presentar todos los elementos de "belleza normativa", solo crea engagement con la audiencia cuando se apuesta por explicar su background y su historia con la complejidad narrativa que requiere. En un principio esta joven aparenta tenerlo todo, belleza, juventud, amigos, proyectos de futuro, posición económica; sin embargo su "yo interno" también sufre de baja autoestima puesto que, para aceptarse a sí misma parece tener la necesidad de ser aceptada previamente por los demás, específicamente por los hombres, aunque para ello tenga que comportarse de forma inadecuada o inapropiada (manteniendo una relación con un profesor) y siendo infiel a sus propios sentimientos (mantener relaciones sexuales con chicos, únicamente para aparentar ser liberada o mayor, sin que medien sentimientos amorosos), ella también es una víctima bajo un bello envoltorio.

También podemos observar un discurso en contra de la existente gordofobia. No sólo nos presenta su existencia, sino que nos relata cómo ésta puede ser eliminada. La serie permite visibilizar los problemas que sufren las personas, en especial las jóvenes que rechazan la percepción de su imagen corporal. Desde los riesgos de la anorexia con la muerte de Tix como como el trasfondo, las causas y los traumas psicológicos que pueden llevar a un/a adolescente a desarrollar una enfermedad mental. La serie es pro-activa a la hora de desestigmatizar el consumo de los antidepresivos, así como explorar los efectos secundarios de estos. No obstante, es cierto que recae en el estereotipo que Harper definía como "equilibrio-crisis-recuperación". Pero cabe destacar que explora una gran variedad de tratamientos psiquiátricos, el internamiento, consultas individuales, grupo de apoyo, y mostrando así la realidad temporal del desarrollo de un tratamiento psiquiátrico. Se muestra cómo afectan de forma positiva las relaciones en el progreso de recuperación y también los contratiempos y regresiones que éstas producen.

Además, mediante los resultados obtenidos podemos observar que Rae se presenta como un modelo a seguir, que rompe con el modelo impuesto de sociedad heteropatrical del héroe que salva a la mujer. Y es que, 
como bien enfatiza My Mad Fat Diary, las enfermedades mentales requieren tratamiento, de la misma manera que lo hacen las enfermedades clínicas de carácter físico, y la depresión no es excepción. Por eso al final cuando ella decide no volver con Finn, apuesta por ella misma y, por tanto, eso es el principio para empezar a superar la situación y supone un paso hacia adelante en su tratamiento, presentándose como una mujer empoderada. La narrativa explora el "yo" como un viaje de superación y, por lo tanto, lo muestra como un éxito. Posee además una gran capacidad de concienciación, y no se recrea en los malos momentos. Rae, pese a todo, es fuerte y capaz, y no lo duda ni un momento. Sabe que podrá con todo, sólo si ella se ve capaz, y eso hace. Rae, como cualquier otra adolescente, descubre que para madurar hay que salir de la zona de confort y eso es lo que sucede cuando se termina el instituto y decide ir a la Universidad por cuenta propia. No obstante, no lo deja todo atrás, Rae no sólo se enfrenta a sus propios problemas, sino que se los lleva consigo, se lleva todos sus errores en la mochila, todo el dolor que ha sufrido, y el que ha infligido en los demás. Se lleva su enfermedad, y se lleva a todas las personas que la han acompañado y la han ayudado a superarla. Por tanto, podemos concluir que la representación de las enfermedades mentales, en concreto de la depresión en My Mad Fat Diary es positiva, con algunos aspectos a mejorar.

\section{Limitaciones y futuras investigaciones}

Las limitaciones del presente artículo es que se trata de un caso concreto. A pesar de ello, permite ser un puente entre los aspectos teóricos y metodológicos, ya que es un ejemplo representativo y paradigmático, que incluye la perspectiva de género. A pesar de la incidencia que esta serie hace en ciertos géneros, la exploración de estos casos en particular permite la construcción de un modelo flexible y adaptativo a otros. En una futura investigación se sugiere ampliar a otras series y géneros.

\section{Declaración de intereses en conflicto}

La autora declara que no existen conflictos de interés potenciales con respecto a la investigación, autoría y/ o publicación de este artículo.

\section{Fondos}

La autora no recibió apoyo financiero para la investigación, autoría y/o publicación de este artículo.

\section{Referencias}

BAmerican Psychiatric Association (APA) (2002). DSM IV-TR. Manual diagnóstico y estadístico de los trastornos mentales. Barcelona: Masson.

Botta, A.R. (2000). The mirror of Television: A comparison of Black and White Adolescents Body Image. Journal of Communication, 144-159.

Chung, et al. (2001). University studentsa attitudes towards mental patients and psychiatric treatment. International Journal of Social Psychiatry, 47, 63-72.

Couture, S. and Penn, D. (2003). Interpersonal contact and the stigma of mental illness: A review of the literature. Journal of Mental Health, 12, 291-305.

Crisp, et al. (2000). Stigmatization of people with mental illnesses. British Journal of Psychiatry, 177, 4-7.

David Cruz, J. (2016). Los resortes narratológicos de la obra de Greimas. Revista escribanía, (11), 2, 85-110.

Del Campo, E., Puebla, B. y Ivars, B. (2016). Las series de televisión: "multiverso" objeto de estudio en Comunicación. Revista científica en el ámbito de la Comunicación Aplicada, (6), 2,13-19.

Dovidio, John; Major, Brenda \& Crocker, Jennifer (2000). Stigma: Introduction and overview. In T.F. Heatherton, R.E Kleck, M.R. Hebl \& J.G. Hull (Eds.), The Social Psychology of stigma (pp. 1-28). New York: Guilford Press.

Draaisma, D. (2009). Stereotypes of autism. Philos. Trans. R. Soc. B: Biol. Sci. 27, 1475-1480.

Espanha, R. (2014). Ficción televisiva y construcción de representaciones sobre salud en Portugal. Portalcomunicación incom UAB.

García González, J. (1999). El análisis del texto literario. Manizales, Colombia: Universidad Nacional.

Goffman, E.(1963). Stigma: Notes on the management of spoiled identity. Englewood Cliffs: Prentice-Hall.

Greenbeerg, Bradley S., et al. (2003). Portrayals of Overweight and Obese Individuals on Commercial Television. American Journal of Public Health, 93 (8), 1342-1348.

Greimas, A. J. y Courtés, J. (1982). Semiótica. Diccionario razonado de la teoría del lenguaje. Madrid: Gredos.

Harper S. (2009). Channelling Affliction: Television Discourses of Distress. In: Madness, Power and the Media. Palgrave Macmillan, London

Henderson, R. (2018). Popular television and public mental health: creating media entertainment from mental distress, Critical Public Health, 28 (1), 106-117.

Himes Susan M. and Thompson Kevin (2007). Fat Stigmatization in Television Shows and Movies: A content Analysis. Obesity, 15 (3), 712- 717.

Hirt, C., Wong, K., Erichsen, S. and J.S. (2013). White Medical dramas on television: A brief guide for educators. Medical Teacher, 35: 237-242.

Hoffner, C.A., and Cohen, L. E. (2015). Portrayal of Mental Illness on the TV Series Monk: Presumed Influence and Consequences of Exposure. Health Communication, 30: 1046-1054, 2015. 
Jenkins, H. (2006). Fans, Bloggers, and Gamers: Exploring Participatory Culture. New York: New York University Press.

Jones, E., Scott, R. and Marcus, H. (1984). Social Stigma: The psychology of marked relationships. New York: Freeman.

Lay, S. (2002). British Social Realism: From Documentary to Brit Grit. UK: Wallflower

Link, B. et al. (2004). Measuring Mental Illness Stigma. Schizophrenia Bulletin, 30, 511-541.

Magallares Sanjuan, A. (2011). El estigma de los trastornos mentales: discriminación y exclusión social. Quaderns de psicologia, (13) 2, 7-17.

Mittell, J. (2015). Complex TV: The Poetics of Contemporary Television Storytelling. New York and London: New York University Press.

Nahum García-Martínez, A. (2014). El fenómeno de la serialidad en la tercera edad de oro de la televisión. En: Fuster, Enrique (Ed.), La figura del padre nella serialitá televisiva (pp. 19-42). Roma: Pontificia Universitá della Santa Croce, ISBN 978-88-8333-350-7.

Niederkrotenthaler, T. et al. (2014). Increasing Help-Seeking and Referrals for Individuals at Risk for Suicide by Decreasing Stigma. The Role of Mass Media. American Journal of Preventive Medicine, 47 (3S2), S235-S243.

Pintor-Holguín, E., et al. (2012). Series médicas en televisión vistas por estudiantes de medicina. Educ Med, 15 (3): 161-166.

Pirkis, J., Blood, R. W, Francis, C., \& McCallum, K. (2006). On-screen portrayals of mental illness: Extent, nature, and impacts. Journal of Health Communication, 11, 523-541.

Pulido Castellanos, F. D. (2000). Teoría de la novela I. Pamplona, España: Universidad de Pamplona.

Sánchez Corral, L. La semiótica de Greimas propuesta de análisis para el acto didáctico. Centro Virtual Cervantes, (26), 470-490.

Sánchez Hernández, M.F., Jiménez-Morales, M. and Carillo Durán, M.V. (2014). Communication and Body Image. Mexico: Pearson.

Strauman, E. and Crandell Goodier, B. (2008). Not Your Grandmother's Doctor Show: A Review of Grey's Anatomy, House, and Nip/Tuck. J Med Humanit, 29:127-131.

T. Frolov y O. Razinkov. (1984). Diccionario de filosofía. Moscú: Editorial Progreso.

Tous Rovirosa, A. (2015). La política en las series de televisión. Entre el cinismo y la utopía. Barcelona: UOC Editorial.

Wahl, Otto (2003). Depictions of mental illnesses in children's media. Journal of Mental Health, 12, 249-258.

Woods, Faye. (2016). British youth television. Transnational teens, Industry, Genre. Berkishire, UK: Palgrave Macmillan.

Wright, S. C. (2009). Cross-group contact effects. In S. Otten, T. Kessler and K. Sassenberg (Eds.) Intergroup relations: The role of emotion and motivation. New York, NY: Psychology Press, (262-283). 


ISBN 978-84-09-20524-0

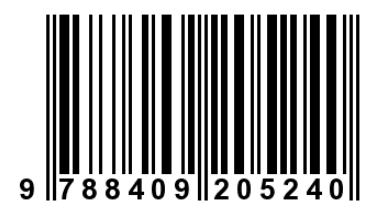

Máster Universitario en Investigación en Comunicación Social (MUCS)

\begin{tabular}{l|ll}
$\mathbf{u} p f$. & $\begin{array}{l}\text { Universitat } \\
\text { Pompeu Fabra } \\
\text { Barcelona }\end{array}$ & $\begin{array}{l}\text { DIGIDOC Grup de Recerca } \\
\text { en Documentació Digital } \\
\text { i Comunicació Interactiva }\end{array}$
\end{tabular} 